\title{
Mimaride Tasarım Kodları ve Anlamsal Sürdürülebilirlik: Dil, Bellek ve Kimlik Tartışması
}

\author{
Hatice Kalfaoğlu Hatipoğlu1 \\ ORCID: 0000-0002-0716-7431
}

*

\author{
Çiğdem Koç Aytekin² \\ ORCID: 0000-0002-5059-034X
}

Öz

Türkiye'deki son dönem mimarlık uygulamalarında tarihi referans kullanımının arttı̆̆ gözlemlenmektedir. Bu geri dönüş ihtiyacının nedenlerini tartışırken, hızla dönüşen yaşamlarımızın güncel dinamiklerini ve mimari tasarımın ilkelerini göz önüne alan tasarımlar ortaya koyabilmek önemlidir. Bugünün mimarlı̆̆ geçmişe duyulan bir özlem içermekte ve geleneksel mimarlı̆̆ı bugüne adaptasyon süreci, karakteristik üslubunun gerçek anlamda anlaşılamadan yorumlanmasina sebep olmaktadır. Fakat bell bekteki bu mimarlik; parçalara ayrılmış, kopukluğa uğramış ve arındırılmaktan ziyade yüzeyselleştirilmiş durumdadır. Bu durum günümüzde nitelik yoksunu, yalnızca görüntü odakl bir mimarlık anlayışı doğurmaktadır. Yeniden canlandırmaya yönelik örneklerle; zamandan, mekândan, bağlamdan, anlamdan ve dilden uzak düşülmektedir. Bu uygulamalarla, tarihten yararlanmanin koşullarının tartışmasının yeniden yapılması gerekliliği ortaya çıkmaktadır. Bu, mimarlı̆̆ doğru iletişimle okumakla ve mimari dil ile yansitılması yoluyla mümkündür.

Bu bağlamda bu çalışma, salt görüntüden ibaret olmayan bu izleri örnekler eşliğinde ortaya koymayı amaçlamaktadır. Bu amaçla, mimari tasarım, bellek-dil-anlam çerçevesinde içerdiği kodlarla ilişkilendirilerek tartışılmış, yazarların Kopenhag ve Malmö şehirlerindeki saha çalışmalarındaki gözlemlerinden edinilen deneyimleri doğrultusunda somut örnekler sunulmuştur.

Anahtar Kelimeler: Mimari kodlar, tasarmm kalitesi, sürdürülebilirlik, kimlik, bellek, mimaride dil ve anlam

\footnotetext{
${ }^{1}$ Dr. Öğr. Üyesi., Ankara Yıldırım Beyazıt Üniversitesi, E-mail: hhatipoglu@ybu.edu.tr

${ }^{2}$ Arş. Gör., Ankara Yıldırım Beyazıt Üniversitesi, E-mail: ckoc@ybu.edu.tr

idealkent @ Kent Araştırmaları Dergisi (Journal of Urban Studies) 


\title{
Sustainability of Design Codes And Semantic Language in Architecture: A Discourse of Essence, Memory and Identity
}

\author{
Hatice Kalfaoğlu Hatipoğlu ${ }^{3}$ \\ ORCID: 0000-0002-0716-7431
}

\author{
Çiğdem Koç Aytekin 4 \\ ORCID: 0000-0002-5059-034X
}

\begin{abstract}
Recently, there is an increase in the use of historical references in architectural practice in Turkey. While discussing the reasons for this need for a return, it is vital to present designs that take into account the current dynamics of our rapidly transforming lives and the principles of architectural design. Today's architecture has a longing for the past. This situation complicates traditional architecture's adaptation process to today and causes the characteristic style to be interpreted incompletely. Architecture is getting fragmented, disconnected and generic, rather than taking place in the collective memory. This situation creates a weak architectural understanding in terms of quality. With examples for revitalization; time, place, context, meaning and language are avoided. With these implementations, it becomes clear that discussions of the current conditions of benefiting from history should be reconsidered and reconstructed. This is only possible through reading architecture truly.

In this context, this study aims to reveal how these traces should be adapted to today with concrete examples. With this aim, architectural design was discussed in relation to the codes within the framework of memory-language-meaning, and examples were in line with the experiences gained from the authors' observations in the field studies in Copenhagen and Malmö.
\end{abstract}

Keywords: Architectural Codes, design quality, sustainability, identity, memory, semantic language of architecture

\footnotetext{
${ }^{3}$ Asts. Prof., Ankara Yıldırım Beyazıt University, E-mail: hhatipoglu@ybu.edu.tr

${ }^{4}$ R.A., Ankara Ylldırım Beyazıt University, E-mail: ckoc@ybu.edu.tr

idealkent @ Kent Araştırmaları Dergisi (Journal of Urban Studies) 


\section{Giriş}

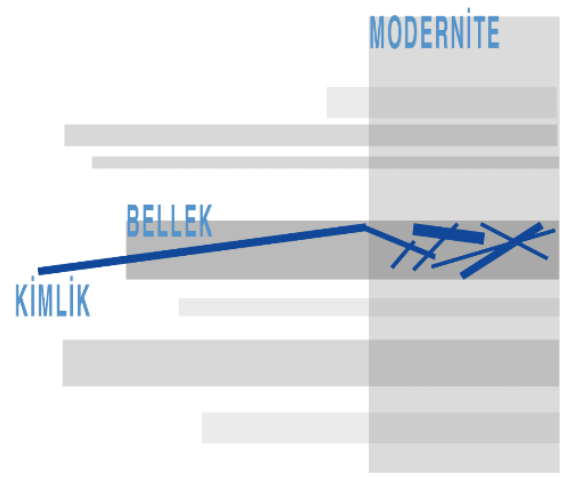

Şekil 1. Bellek, Kimlik ve modernizm canlandırması ( Kaynak: Yazarlar)

Modernizmin, Anadolu'daki geleneksel mimarinin karakteristik üslubunu sorgulatma süreci, bugünün mimarlık anlayışını bir kimlik tartışmasıyla karşı karşıya bırakmıştır. Bu kimlik karmaşası ve günümüzün 'arada'lı̆̆ı ile birlikte; tasarımda, önceki dönemlerdeki pratiklerden elde edilen bilginin yeni ve güncel ortama adapte edilme süreci, bellek ve mekan arasındaki doğru ilişkinin sorgulanmasını da beraberinde getirmiştir.

Batı Avrupa'da hızlı ve yaygın bir değişim ve dönüşüm olarak yaşanan modernite, süreklilik duygusunun yitirilmesi sonucunu doğurmuştur (Şekil 1). Geleneksel Türk mimarlığının bellekteki anlamsal sürekliliği de modernizm ile sekteye uğramış, imge ve bellek birbirinden uzaklaşarak zaman ve deneyim süreksizleşmiştir (Parmaksız, 2019). Günümüz Türk mimarlı̆̆ında, beğeni odaklı bir tasarım anlayışının hakim olduğu bir süreçte olduğumuz söylenebilir. Belleğe yönelik tutumun dönüşümü, 'unutulmasından korkulanlar'ın, kütüphanelerde, arşivlerde, müzelerde veyahut mimaride imgeler aracılığıyla korunmasına sebebiyet vermiş̧ir. Belleğin bu şekilde dışsallaşması, geçmişe yönelik nostaljik refleksin bir ifadesi olarak görülebilir (Jedlowski, 2001). Başka bir ifade ile, geçmişte özlem duyulan imge/mekan olgularının formel devamlılığı, 'arşiv' adı altında stoklaştırılarak karşımıza çımaktadır. Toplumsal beğenilerin zamanla değişmesiyle birlikte mimarlık disiplinini geçici bir modaya sevk eden bu görüş, günümüz Selçuklu-Osmanlı cephe modasında kopya ve taklit ile kendini açığa çıkarmaktadır. Dahası, bugün Anadolu mimarlığında, bu kimlik sorununun, ancak geçmiş ve geleceğin tarihselci çizgisinde cevap aradığı gözlemlenebilir (Balamir ve Asatekin, 
1991). Geçmişte de çeşitli dönemlerde günümüz benzeri örnekler incelendiğinde, 'geleneksel üslup' ve 'ulusal kimlik' adı altında uygulanan pratiğin, aslında bağlamı ve günün şartlarını göz ardı eden, doğadan uzak, sanal ve yüzeysel bir tekrarın kurbanı olan bir tasarım anlayışına sahip oldukları aşikardır. Bozdoğan'a göre, geçmişteki klasik bir dönemi bugün için en uygun mimari paradigma olarak sabitleme çabası (Osmanlı Canlandırmacılığı) Türk mimarlığ için bir kimlik bulma girişimidir (Bozdoğan, 2001). Türk mimari kimliğini bu çerçevede anlamaya çalışmak, yitirilen/özlem duyulan bir geçmişte ya da idealize edilerek kurgulanan bir gelecekte, yani, o an'a özgü koşulların göz ardı edildiği bir çerçeveye sığdırmakla eşdeğer görülebilir. Kuran'ın da vurguladığı gibi modern zamanlardaki tüm tarihsel yeniden canlandırmacılıklar, biçimsel ve entelektüel çıkmazlar gibidir (Kuran, 2012). Halbuki, Anadolu Türk mimarisinin farklı coğrafyalarda gelişimi ve dönüşümü değerlendirildiğinde, üslup seçiminin belirli bir ideoloji veya kimlik tanımlamasından çok, somut çevresel/ dönemsel şartlar, kültürel etkileşimlerden ve bağlamdan nasibini aldığı aşikardır.

Sürdürülmek istenen özü, zaman ait üslup seçimini ve tasarım kararlarını anlamak ve anlamlandırmak için mimarideki kodları analiz etmek gerekir. Kod kavramı, herhangi bir mesajın unsurlarını veya birimlerini birbiriyle ilişkilendiren ve anlaşılmasını mümkün kılan organizasyon veya sisteme atıfta bulunur. Arkitektonik kodlar ise, organize mimari fikirler veya bunların organizasyonu için kural dizileri ve karmaşık mimari birimler oluşturmak için mimari fikirlerin veya kuralların seçilmesini ve birleştirilmesini sağlayan metafor ve metonim işlemler olarak tanımlanabilir. Metonimi, bir mesajın kendisinde bulunan öğeleri kendi iç kombinasyonları ile birbiriyle ilişkilendiren bir işlemi ifade ederken metafor, bir mesajı, öğelerinin yer değiştirilmesi veya seçilmesiyle bir koda bağlayan bir işlemi ifade eder. Aynı zamanda, bu öğeleri bir kod aracılığıyla ilişkilendirerek, mesajda var olan öğeler ile mesajda bulunmayan öğeler arasında, bunların yerine geçebilecek bir bağlantı kurar (Jakobson, 1971). Bu kodlar, sabit bir çerçeve içinde yapılandırılmış bir mimari fikirler bütünü olarak değerlendirilse de bu mimari kod anlayışının mimarinin özündeki karmaşıklığı önerebilmesi için mimari kod daha çok, sadece mümkün olan mimari ilişkilerin boş bir çerçevesini oluşturan karşıtlıklara dayanan dinamik bir gerilim alanı olarak görülebilir. Bu çerçeve, mimari formun altında yatan sentezi oluşturmak için tasarlanan bina fikirlerinin, imgelerinin ve kavramlarının içerisinden geçmesi gereken yerdir (Gandelsonas ve Morton, 1972). Mimari tasarımda özün ve kalitenin sürdürülebilmesi için bu kodların doğru bir şekilde anlaşılması ve uygulanması önemlidir. Binalar 
ve kentsel alan, eleştirmenler tarafından üretilmekten çok, genellikle dış temsiller olarak kabul edilir, anlamları keşfedilir.

Mimarideki kodları -anlamları- keşfetmek için dile doğru yoğun bir geçiş olmuş, doğal ve sanatsal diller arasında bir ilişki kurulmuştur. Mimarlık hakkında, özellikle yüksek modernist gelenekte yazmak, tipik olarak, binaların, alıcı gözlemciye özerk bir şekilde anlam aktardığını varsayar: metinler, bu anlamları düşünür ve yansıtır, ancak kaynakları değildir (Crysler, 2003). Adrian Forty (2000), mimari modernizmde anahtar kelimelerin değişen anlamının izini sürerken ve dilin sadece binaların gerçekliğine bir tamamlayıcı olmadığını, ancak onlarla ilgili deneyimlerimizi yapılandırmada aktif bir rol oynadığını savunmaktadır. Foucault ve White gibi yazarlar bu durumu sorgular ve argümanları, dünyanın diğer yönlerini anlamamız gibi, binalar hakkındaki anlayışımız için de dil öncesi bir anın olmadığını belirtmektedir (Foucault, 1971; White, 1978).

Bu ilişki aynı zamanda bir benzerliğe, yani mimarinin de bir dil gibi okunabileceği anlamına da evrilmiştir. Çeşitli araştırmalar sayesinde farklı kültürlerin ve halkların dillerinin bazı ortak kuralları ve dilin birimlerinin sistem yapı benzerlikleri olmasına rağmen, yapı, kelime bilgisi ve dil bilgisi olarak farklılıklar gösterdiği bilinmektedir (Foucault, 2002; Eco, 1986). Benzer bir durum mimari dilde de söz konusudur. Mimarinin kavramsal dili biçim, işlev, tektonik, ölçek, oran, simetri, ritim vb. gibi birçok kavramı içerir. Mimarinin morfolojik dili ise mimari kompozisyonda fikri ve sanatsal niyeti somutlaştırmaya izin veren özel bir sanatsal dil olan mimari şekillerin dilidir. İkisi arasında ayrılmaz bir bağ vardır. Sanatsal bir şekil olarak düzen, dışavurumcu bir mimari araçtır (bilgilendirici, işaret eden, dekoratif, sembolik, imgesel). Algılayan kişiye belirli bir (sanatsal) içeriği -metni- iletmesi planlanır (Remizova, 2015). Böylece düzen, sadece oluşturan için değil, algılayan için de anlaşılabilir özel bir dil veya işaret sistemine dönüşür. Neticede mimari ve dili semantik (anlam), sentaktik (yapısal), literal (kompozisyon), dil (genel bir sistem) alt başlıklarında kıyaslamak ve benzeştirmek mümkündür.

Bunun yanı sıra, yerel mimarlığın sahip olduğu özgün iletişim dili, tarihsel süreçte süreklilik arz eden birtakım olgular vasıtasıyla algılanabilir duruma gelir. Bu olgular, bölgenin coğrafyası, sosyolojik ve ekonomik durumu, iklimi gibi verilerden etkilenerek yerel mimari karakteri oluşturur ve dönemin şartlarına göre farklılık gösterirler. Bu kapsamda Anadolu geleneksel Türk mimarlı̆̆ının tarihsel süreçte elde ettiği bellekteki anlamsal sürekliliğin doğru algısı, yani bu dilin doğru okunması günümüz ve gelecek yılların mimarlığına sşık tutabilmesi için önemlidir. 
Eleştirilen canlandırmacı mimarlık üretiminin aslında ulusal kimlik adıyla çıkış yaparak, asıl amaçlanan ve sürdürülmesi istenen tutumdan ne kadar uzak bir tavır takındığı sorgulanabilir haldedir. Bu bağlamda bu çalışma, mimarlık ürününün kendinden bir önceki ve bir sonrakiyle kurduğu ilişkinin pratiğe nasıl yansıdığı üzerinde duracak, bu ilişkiler bütünü içinde sürdürülebilir olan mekânsal hafızanın/ anlamın/ felsefenin ve kimliğin, diğer bir deyişle 'öz'ün arayışı içinde olacaktır.

$\mathrm{Bu}$ çalışmada, tasarım sürecinde, karakteristik olguların tasarımda nasıl kullanıldığı ve nasıl karşılık bulduğu birkaç somut örnekle sergilenecektir. Örnekler yazarların bu bağlamda Kopenhag ve Malmö şehirlerindeki saha çalışmalarındaki gözlemlerinden edinilen deneyim ve algılar üzerine kurgulanmıştır. Bu sayede 'öz' ve 'özgünlük' arasındaki ilişki incelenerek, 'kimliklerinden koparılmış imgeler'den oluşan günümüz mimarlığ için gelecekte tutunabilecek somut bir düzlem elde edilmeye çalışllacaktır. Bu çerçevede, çalışmanın amacı, doğru mekan algısıyla yerel/geleneksel/nitelikli mimarllğın anlamsal sürekliliğinin bellek/mekan tartışması çerçevesinde nasıl sağlanabileceğini araştırıp somut örneklerle sunmaya çalışmaktır.

\section{Mekânsal Kodlar; Dil, Bellek ve Anlam İlişkisi}

Mimaride iddialı bir modernist gündemin ortaya çıkışından bu yana, görsel formların ve görünmez niteliklerin anlamlarını keşfetmek için dile doğru yoğun bir geçiş olmuştur. Bu süreç, Laugier'in ve Edmund Burke'nin on sekizinci yüzyılda "karakter", "hafıza" ve "işlev"e yönelik daha sistematik olan yaklaşımıyla başladı, on dokuzuncu yüzyılda John Ruskin ve diğerlerinin "gramer" ve "özgünlük" hakkındaki sorularıyla devam etti ve yirminci yüzyılda minimalist formların birbirini izleyen aşamalarını açıklama çabalarıyla yoğunlaştı (Forty, 2000).

Anlam, iletişim kurmak için üzerinde mutabık kalınan kurallar sistemi olan dil yoluyla aktarılabilir. Dil üzerinde gerçekleştirilen belirli işlemlerin ürünü veya dilin kendisinin işleyişi olarak görülebilir (Greimas, 1983). Modern anlam biliminin (semantik) belirli alanlarındaki önemli önermelerinden biri olan dil, heraklit akışının en göze çarpan modelidir. Auguste perret, "mimari unsurların - sütunların, kirişlerin, kemerlerin, duvarların, açıklıkların, tonozların ve döşemelerin - pratik gereksinimlere ve duygusallı̆ga göre sonsuz çeşitlilikte bir araya getirilebilen bir kelime dağarcığıyla karşılaştırılabilir olduğunu belirtir. (Collins, 1959) Sözlü kelimeler gibi, bu unsurlar, değişen sosyal koşullar nedeniyle değiştirilebilir veya hatta tamamen dönüştürülebi- 
lir. Algılanan zamanda her an değişim içindedir. Dil ile ilişkili olay/durumların toplamı yalnızca artmakla kalmaz, aynı zamanda her yeni olay tarafından nitelendirilir (Steiner, 2013). Tschumi'ye göre mimariyi dil ile özdeşleştirmenin birçok yolu vardır ancak bu tür denklemler genellikle bir azalma ve bir dışlama anlamına gelir (Tschumi, 1977). Sonuç olarak mimari ve dili semantik (anlam), sentaktik (yapısal), literal (kompozisyon), dil (genel bir sistem) alt başlıklarında kıyaslamak ve benzeştirmek mümkündür.

Mimaride anlam, birbiriyle ilişkili iki yön açısından tanımlanabilir; ilki, bir binanın bileşenlerini, alt bileşenlerini, sistemlerini ve alt sistemlerini yapılandırmak için bir dizi olasılık; ikincisi, mimari bir bilgi havuzundaki, imgelerin ve fikirlerin bir repertuarı. Bu modelle, mimari sistemin anlamsal boyutları, biçimsel desenlerini mimarinin kendisinden veya resim, müzik gibi herhangi bir yerden çekebilen birinci, özellikle arkitektonik yön ile ikinci bilgi havuzu olma yönü arasında bir sentez olarak görülebilir. Mimari yön biçim sağlamaz, yalnızca biçim yapılandırma olanağı sağlar; bilgi havuzu olma, yani anlam yönü ise gerçek biçimsel modellerin kaynaklarını sağlar (Gandelsonas ve Morton, 1972). Yani mimariye bir anlamlandırma sistemi olarak yaklaşmak yanlış olmaz. Eisenman ve Graves, bir anlamlandırma sistemi olarak mimariye özgü ana ve belirli yönlerden birine odaklanmıştır. Morris, her anlamlandırma sisteminin üç karakteristik boyuta (semantik/ anlambilimsel-, sentaktik/ sözdizimsel ve pragmatik) sahip olduğuna işaret etse de, Eisenman ve Graves için birincil ilgi alanlarından yalnızca ilk ikisi budur. Morris'e göre "anlambilim", işaretlerin (bir şeye atıfta bulunan), onların tanımlanmalarıyla (neyin hesaba katıldığı) ve böylece gösterebilecekleri veya gösteremeyecekleri nesnelerle olan ilişkisiyle ilgilenir. "Sözdizimi" göstergelerin nesnelere veya yorumlayıcılara olan ilişkisinin soyutlanarak işaretlerin birbirleriyle ilişkilerinin incelenmesidir. (Morris, 1970; Gandelsonas ve Morton, 1972)).

Dildeki anlamsal ve sözdizimsel fark mimaride de görülür. Mimarın içselleştirilmiş düşünceyle tasarladığı gibi mimari form dişsal bir sorunla ilişkilendirilmek durumunda kaldığı için anlamsal çizgiler doğrultusunda gelişmiştir. Öte yandan mimarinin temeli bir problem çözme sistemi olarak işlevinde yattığ için, mimarinin bu aktivitede ona rehberlik edecek bir dizi sözdizimsel kavramlar inşa etme durumu ortaya çıkmaktadır. farklı mimari unsurlar arasındaki olası ilişkiler veya unsur gruplarının kombinasyonları için belirli yönergeler olsa da bu talimatlar esas olarak dış problemlerin çözümü ile ilgilidir ve nihayetinde sadece dış ihtiyaçlara bağımlılığı pekiştirir (Gandelsonas ve Morton, 1972). 
Bu durumda arkitektonik/mekânsal kodların analizi, 'tipik', 'örnek' veya (dışsal olarak) kayda değer 'anıtlar' yerine, eşzamanlı olarak belirli bir ortamı içeren, bir arada mevcut oluşumların toplamına ihtiyaç duyar. Arkitektonik kodun kökenleri, işlevsel ve biçimsel organizasyonunun anlaşılmasıyla amansız bir şekilde bağlantılıdır. Formların anlamlı bağlamları dışında kendilerine ait bir yaşamları yoktur ve binalar, zaman içinde tek çizgili ya da soysal anlamda değil kümülatif bir şekilde bağlantılı seriler oluştururlar. Yapılı çevrelerin analizine dair göstergebilimsel bir bakış açısı, bir kültürün yapılı çevresinin eş zamanlı sistematikliğine odaklanarak, mimari artzamanlılığın biçimsel organikliğini telafi eder (Preziosi, 2008). İşaret verilerinin farklılaşmasının temelinde, mimari kodda iki tür işaretin var olması yatar. İnşa edilmiş bir çevrenin bileşenleri, doğrudan ya da dolaylı olarak anlamlıdır ve bu, anlam ile işaret verileri arasındaki ilişkinin doğasına dayanan bir ayrımdır. Hem dilbiliminde hem de mimaride doğrudan ve dolaylı anlama sahip olanlar olarak iki tip kodlanmış birim vardır. Dolaylı anlatım olarak, bir nevi soyut anlatı içeren kodlar, yani öz ve anlama ilişkin değerler; doğrudan anlatım ise formel olgular, yani imge ve malzeme olarak örnek verilebilir.

Literatürde, deneyimin ve yaşanmışıkların inşası olarak tanımlanabilecek mimarlık disiplini için bellek olgusunun önemli bir çalışma haline geldiği görülmektedir. Örneğin, bireyin "iç"ine yönelten bakış açısı ile Bergson, geçmişin geçmişte kalmadığını savunarak bedeni/benliği gelecek ve geçmiş arasındaki hareketli bir sınır olarak tanımlar (Bergson, 2015). Ona göre bellek 'süre' olarak zaman kavramına dayanır. Dolayısıyla, geçmiş, bireyi daima izler ve bu iz ömür boyu topladı̆̆ı şimdiyle durmadan büyür. Ona göre zaman ve bellek iç içedir ve bilinç hafızadan bağımsız düşünülemez.

Asla tek başımıza anımsanamayız.

(Halbwachs, 2018)

Bergson'un aksine sosyolog Maurice Halbwachs, Kolektif Bellek isimli başlı̆̆ıyla yayımlanan metinlerinde, belleğin mekan ile ilişkisini toplumsal yaşam çerçevesinde değerlendirerek yeni bir bakış açısı geliştirmiştir. Halbwachs ile birlikte bu kavram, toplum ve gruplar içinde oluşan kollektif düşünceler bütünü olarak düşünülmeye başlanmıştır (Halbwachs, 2018). Bireysel ve kolektif olarak iki düşüncenin gölgesinde tartışılan hatırlama ve bellek kavramları, zamanı ilk olarak geçmiş kavramıyla ilişkilendirmiştir. Mekandan soyutlanan bireyin 'iç'ine yönelten düşüncelere dayalıydı. Geçmişi geleneğe dönüştürmede yetersiz kalan insan merkezli bellek anlayışları, ge- 
lenek meselesini bir sorun olarak kucaklarında buldular. Geçmiş ölüme mahkum edildiğinde, gelenek bir sorun haline geldi. Bu nedenle, bir "zaman" olarak geçmişi yaşatmayı sağlayacak yeni bir "hatırlama" anlayışına ihtiyaç duyulmuştur. Assmann, "geçmişin, ancak kendisiyle ilişki içinde olunması halinde" ortaya çıktığına temas eder. "Bellek sanat için mekân neyse, hatırlama kuiltư̈ü için de zaman odur" diyerek bu durumu perçinler. Bu doğrultuda bir önerme de, merkezine zaman kavramını alarak dünü yok olmaktan kurtarmak ve hatırlayarak yaşatmak düşüncesine göre bir bellek anlayışı sunar. Assman'a göre bu geçmişin hatırlanarak yeniden kurulması düşüncesidir. Fakat bu yeniden inşanın, kültürden, temsilden ve şimdiki zamanın bağlamından bağımsız gerçekleştirilemeyeceğini ifade eder (Assmann, 2001).

Belleğin, kodlama, saklama ve gerektiği zaman geri çağırma olarak tanımlanabilecek üç aşama içerdiği söylenebilir. Kodlama, bilgiyi belleğe yerleştirir; saklama, muhafaza eder; geri çağırma ise tekrar kullanıma sunar. Bu çerçevede mekanı anlamlandıran somut ve soyut bazı özelliklerin algıda sürekliliği sağladığı söylenebilir. Bu yaklaşımlar doğrultusunda hafızada yer edinen mekanın kimliğini meydana getiren olgular tanımlanabilir hale gelmektedir. Sözlü dil ve inşa edilmiş çevreler, günlük yaşamda devam eden anlam orkestrasyonu içerisinde farklı / sürdürülebilir bileşenler olarak, tamamlayıcı ve destekleyici tarzda dinamik bir eşzamanlılık ile etkileşim halindedir. Mimari nesneler, kütleler, boşluklar, malzemeler, renkler, dokular ve göreli boyutlar arasındaki koda özgü ve kural tarafından yönetilen zıtlıklar ve karşıtlıklar aracılığıyla ifade edilen desenli, üç boyutlu olarak sentagmatik dizilerden oluşur. İnşa edilmiş çevreler, vizyonun yönlülüğünü ve geçiciliğini ele almak için oluşturulur. Zamanla parça parça okunurlar. Bir arkitektonik nesne statik bir sahne seti veya zemin değildir ve bir oluşumun her bileşeni, hem görünür hem de potansiyel olarak görünür olan bitişik bileşenlerin dizinsel ve metonimik olarak okunmasını gerektirir (Preziosi, 2008). Yani yapılı çevre, göstergeler arasındaki bir ilişkiler sistemidir. (formlar ve malzemeler arasında değil). Temel olarak başka bir deyişle, inşa edilmiş ortam, işaretler arasındaki ilişkiler sistemidir. Bir kültürün okunması simgelerle olur. Bunlar görünür/görünmez, sözlü/sözlü olmayan şekillerde olabilir. Lefebvre'nin (Lefebvre, 2014) mekanın kavramsal, toplumsal ve maddi yönlerini birbirine bağlayan üniter teorisi, mekanı bir sosyal üretim aracı olarak tanımlar ve bu üç alanın biçim, anlam ve icra edilişinin öngörülerine odaklanarak sosyal mekanın analizi üzerine bir perspektif oluşturur. 
Mekansal kodların sürdürülebilirliğini günümüzdeki eğilime benzer bir şekilde, somut değerlerden biri olan form üzerinden sağlama eğilimi mimarlıkta zaman zaman ortaya çıkmış, hatta yaygınlaşarak bir üsluba dönüşmeye meyletmiştir. Örneğin Avrupa'da 19.yy ortalarına doğru arkeoloji biliminin de popülerleşmesi ile birlikte Antik Yunan dönemine ait bulgularla o dönemin mimarisine ait detaylar ortaya çıkması ve halkın bunları görmesiyle Avrupalılar klasik dönemlere öykünmeye başlamışlardır. Bu dönemde yapılar geçmişe ait dekoratif detaylar barındırmaya başlamış ve bu detayların artışı mal sahiplerinin güçleri ile doğru orantılı kabul edilmiştir. Bu dönemlerde mimarlık mesleğine başlayan Loos, eklektik cephe süslemelerinin yaygınlaşmasıyla şehrin adeta bir sergi haline gelmesini eleştirir (Loos ve Stuiber, 2012). Potemkin şehri adlı makalesinde Rus Çariçesinin geçerken görmesi için gerçekten bir şehir varmış gibi maket cepheler yerleştirerek yapılan Potemkin şehrine benzetir bu sergilemeyi. Bu görünümlerin arkasında ne gerçek bir şehir ne de gerçek bir yaşam vardır. Mimarlığın formel bir dile indirgenmesi, yaşam sunan bir olgu olduğunu unutturmuştur.

Mimarın yaşamın geçmişiyle doğru bir ilişkisi kurmasının yolu kalıcı ve geçici değerlerin farkındalığı ile olur (Loos ve Stuiber, 2012). Ona göre süslemeler, insanların deneyimini kısıtlayarak mekanı sergiye dönüştürmektedir. Halbuki, mekan deneyimlendikten sonra akılda kalandır. Yani gelenek, mükemmelliğe ulaşmak için kimliğin gelişmesini sağlayan araçtır. Loos'un bu anlayışı, modern insanın bir hikayeye da bir söyleme özenmesine engel olur. Diğer bir deyiş̧le, $\mathrm{O}$, mimardan içinde yaşadığı zamanı, durumu anlayarak ondan kendi çağını inşa etmesini beklemektedir.

Bu bağlamda, mimaride dil, gücünü gelenekler ve kültürel kimlikten alır ve mekanın semantik içeriği anlamlı bir çevrenin inşası işe mümkündür. Zaman çizgisinde algının hafızada sürdürebildiği en somut izlerden biri olan 'malzeme', kompozisyon kapsamında mekanın bileşenlerinin birbirleriyle ve çevreyle ilişkisini sorgulatan 'oran ve bağlam', ve gündelik yaşamda görüntü olarak indirgenen fakat aslında zihinsel bir sürecin ürünü olan 'imge' belleğin incelenebilir ve sürdürülebilir kıldığg özelliklerden birkaçıdır.

\section{Malzeme}

Mimaride malzemeler kullanılırken malzemelerin doğasında olmayan duygular uyandırılır. Geleneksel mimarideki malzeme kullanımının çağdaş mimarlıkta karşılık bulabilmesi, hafızada anlamsal niteliğinin yitirilmeden taşınabilmesiyle mümkündür. Malzemenin doğasına bağlı kalma durumu mimarlık tarihinde 18. yüzyılda tartışmalara açılmış ve tasarımın en temel 
öğelerinden birisi olarak görülmüştür. Bir yapı bileşeninin oranları, malzemesi değiştirildiğinde değişir düşüncesi Frank Lloyd Wright' ın mimarlık teorisinin gelişiminde de önemli bir etken olmuştur. Wright için malzemeye sadık kalmak malzemenin niteliklerinin farkında olmak önemli bir tutumdur (Wright, 1975). Hafıza dünyasında bu tutumun sürekliliği, mimarlığın biçim ve anlam ilişkisinin yaşam döngüsü arasında konumlanır.

Anadolu geleneksel mimarisinde malzeme seçimi yapının uzun ömürlü ve az tamir gerektirmesine yönelik yapılmıştır. Dolayısıyla bölgenin dış etkilerine dayanıklı malzemeler özellikle seçilmiştir. Bu tür özellikler incelendiğinde bize geçmişimizde adı konmamış bir "sürdürülebilirlik" kavramının varlığını işaret eder. Bazı medeniyetlerde malzeme seçimi konutlar dışındaki yapılarda her zaman uzun ömürlü ve sağlam malzemelerden yana yapılmıştır. Bu sayede yapıların uzun süre ayakta kalabilmesi ve daha az bakım gerektirmesi amaçlanmıştır. Örneğin, Ankara'da, tuğla örgü dışta gösterilip, duvarın iç yüzü sıvanmaktadır. İçte-dışta ahşap çıtalama üzerine sıva yapılması, arada kalan boşluğun, bir ölçü uyarınca giriş çıkış delikleriyle havalandırması, yüksek, nemli, llıman iklim bölgelerinde çok karşılaşılan bir yöntemdir. (Bektaş, 2013). Malzemenin bu kullanımı kusursuz bir sıcak-soğuk yalıtımı sağlamaktadır. Bu örnekten anlaşılacağı üzere, malzemenin binanın inşa edildiği yere ait olması bir yandan sürdürülebilirlik kavramını desteklerken, bir yandan da tarihteki bir modelin aslında her yere uygun olmadığını, dolayısıyla yerden bağımsız tekrar eden bir "model" haline gelen binaların ne denli “öz" den uzak olduğunu vurgulamaktadır.

\section{Oran ve Bağlam}

Le Corbusier için kütleler algılanabilir oranlara göre düzenlendiği zaman gerçekliklerini elde ederler. Algılanabilir olma, insan odaklı bir kurgu anlamına gelir, dolayısıyla insanın ölçeğine göre inşa edilmiş tüm mekanlar dikkate değerdir. Şark Seyahati'nden elde ettiği yaklaşım Le Corbusier'in insan boyutlarının sırrı geleneksel yerleşimlerdeki çözümlere dayanmaktadır (Corbusier, 2000). Anadolu'daki geleneksel mimari incelendiğinde, kontrolden çıkmış bir oranın mümkün olmadığı, her şeyin birbiriyle, yerin ruhuyla ve insan ölçeğiyle uyum içinde olduğu, abartılmadığı veya yok sayılmadığı gözlemlenir. Yapının kendi içinde, çevresiyle ve insan ölçeğinde sağladığı bu oran/orantı ve uyumu önemli değerlerdendir. Örneğin geçmişimize ait organik mahalle oluşumlarında doğaya zarar vermeden, ağaç kesmeden oluşan sokaklar vardır. Aynı özenli yaklaşım yapılarda da görülmektedir. Tasarımlarda doğaya negatif müdahalelerden kaçınılır ve onlara yüklenen anlamlar 
vardır. Yapı tipleri gelişigüzel oluşmamıştır, mahalli yapı tekniği ve ihtiyaçlardan doğan ve şekil bulan şuurlu bir mimarinin ürünüdür (Kuran, 2012).

Rasmussen mimarinin kendine özgü doğal oranlama yöntemleri olduğundan bahseder. Fakat görsel dünyadaki bu orantıların müzikteki armoniler gibi algılanacağını düşünmek hata olur. Her ne kadar kibrit kutuları gibi tek başına nesneler için insana daha çekici gelen belli oranların olduğu görülmüş olsa bile, genel olarak ele alındığında mimaride sadece belli oranların doğru oranlar olduğunu düşünmek doğru olmaz. Gotik katedrallerindeki enfes etki, yüksekliği eninden katlarca fazla duvar modülleri sayesinde gerçekleşir. bu modüller tek başına gözlemlendiğinde kimseye çekici gelmeyecektir. Mekanın doğasıyla meydana gelen bu uyum/ritim, bellekte de parçaların bir araya geldiği haliyle yani bağlam ile birlikte kalıcı olacaktır (Rasmussen, 2009). Örneğin Osmanlı klasik döneminde pencere ve kapıların en boy oranlarında belli bir düzen yakalanmaya çalışılmıştır. Çoklu pencere dizilimleri bir kemer ve/veya çerçeve içinde ele alınmıştır. Bu dizilim rastlantısal değildir ve cephe elemanları arasında belli bir oran ve kurgu oluşturulmuştur. Binalarda ortak bir oran/düzen ve üslup takip edilmesine rağmen bina cephelerinin birbirinin tekrarı ve kopyası olmaması bize özgün bir tasarım arayışının var olduğunu gösterir. Evlerin alçak gönüllü, narin yapılar olarak vücuda getirilmelerini, çekingen bir tavırla tabiatı incitmeksizin peyzaja adeta ilişmelerini, komşuları ve çevreleri ile bütünleşmelerini sağlamak tasarımın ana amacı oldu. Bu amaçla, yapı birimlerinin ölçü düzenleri, malzeme ve renkleriyle, geçmişte olduğu gibi varlıklarını borçlu oldukları doğayla uyumlu, onu daha güzel kılan unsurlara dönüşmelerini sağlamak üzere iddiasız, her türlü şatafattan uzak, yalın bir mimari dil tercih edildi (Öğün ve Öğün, 2001).

\section{Imge ve Üslup}

Kent ve mekan, yaşantıdan kaynaklanan gerçekliğini imgeler yoluyla ifade ettiği söylenebilir. Alvaro Siza'ya göre imgeleme, belleğin bizlere kazidıklarını ve belleğin koşullar ve zorunluluklar karşısına çıkardıklarını anımsamak demektir (Siza, 2015). Mekana dair imgenin kurucusu; mekanın fiziksel varlığ1 ve deneyimleyenin belleğindeki iz olarak yaşamla birlikte bu izin dönüşmesiyle oluşan anılardır. Fiziksel varlığının hiçbir izi kalmamış dolayısıyla deneyimlenme olasılığı ortadan kalkmış mekanların imgesinin devamlılığına anılar kaynaklık etmektedir. İmgenin varlığının fiziksel varlığa bağımlı olmadığı açıktır. Dolayısıyla mekanın fiziksel varlığının yok oluşu mekanı yok kılmaz. Başka bağlamlarda da olduğu gibi asıl yok oluş, imgenin 
silinmesidir (Serim ve Ünlü, 2007). Çünkü imge, deneyimler silsilesi olarak yaşam ile ilişkilidir; belleğin ve anın bir aradalığının onaylandığı düzlemde yaşamın kendisi bağlamda iz sürülebilmesini sağlar.

Mekan/kent tanımlı bir üslup doğrultusunda bellek ile imgesel ilişkilerini kurar. Mimarlık ve şehircilikte farklı dönemlerde farklı üsluplar gelişmiştir. Üslup kelimesi bir çağın en yüksek noktasını anlatmaktadır. Ancak üslubu bu şekilde değerlendirirken sinırları keskin dağın zirvesine bakmanın yanında dağın kendisinden de söz etmek daha anlamlı olacaktır. Ayrıca bu üslupların her birinin en yüksekte olduğu noktada bir sonrakine evrilmiş ve bir zincir oluşmuştur (Wagner, 1990) Her yeni üslup bir öncekinin temeli üzerine kusursuzlaşıncaya ve dönemin idealine uygun oluncaya kadar gelişmiş ve yeni malzemeler, teknikler, çağına uygun yeni anlatım biçimleriyle harmanlanarak oluşmuştur.

Dahası, mimarlık farklı etkenler sonucunda birbirine benzeyen özellikte yapılar sergiler ve zamanla bu özelliklerin bir şahsiyet/karakter kazandığı görülür. Bunun sonucunda bir dönemde yapılan eserler ortak bir tavrı benimser; bu ortak tavır ve karakter üslubu oluşturur. Ancak her üslup teknoloji, sosyal yapı, vb. Çeşitli değişimlerin etkisi sonucu oluşan yeni akımların yerine gelmesiyle ömrünü tamamlar.

Bu üslubu oluşturan eserlerdeki biçim ifadeleri mimarların duygu, değer ve tavrının esere yansıması, dolayısıyla toplumun bir ferdi olduğundan o dönemdeki değerleri de ifade eder. Kültür ve medeniyete has bazı değerler değişmez, ancak mimarların bu değerleri esere yansıtma biçiminin bu akımlara göre değişmesi normaldir, hatta mimari özgünlüğün oluşması için beklenendir.

Berger'e göre bir imge herhangi bir medya alanında görülen şeydir, dahası, insan bilincinin ürünüdür. İnsan bilinci ise kültür ve tarihin ayrılmaz parçasıdır. Berger' in ifade ettiği gibi imgeler sosyal ortam içinde belirli işlevler üstlenirler. Bu nedenle bu imgelerin söz konusu bağlamın dışından anlamlandırılması güçtür. İmgelerin kültürün ve bağlamın ayrılmaz bir parçası oluşu geleneksel mimarinin birçok özelliğinde kendisini gösterir (Berger, 2008). Dolayısıyla geçmişteki hiçbir üslubun sonraki zamanlarda geçerliliğini koruyamadığı ancak bu üsluplarla yapılmış birçok yapının taptaze günümüze kadar geldiği görülmektedir. Pratik işlevlerini kaybetseler de, teknolojileri geçerli olmasa da bu faktörlere rağmen hala canll, yol gösterici ve öğreticidirler. Bu eserlerin kalıcığını sağlayan yaklaşım yapıldıkları dönemin üslubunda değil, içerdikleri mimari düşüncededir. 


\section{Öz'ün Sürdürülebilirliği}

Mimarlığı göstermek için mimarlığın özünü tanımlayacak bir yöntem bulmak gerekir (Zevi, 1957). Bu çalışma bu öze dikkat çekerek günümüz Türkiye'sinde yanlış anlaşılan geçmiş canlandırmacılığını eleştirel bir bakış aç1sıyla ele almıştır. Çünkü zaman zaman dünyada geçmişin replikası olan, geçmişteki biçimleri birebir taklit eden akımlar olsa da, bu akımlar uzun süre mimarlık arenasında tutunamamıştır. Her dönemin kendine özgü bir dili olmalıdır ve her dönem kendi gereksinimleri (sosyal, kültürel, teknik koşulları) kapsamında (birebir kopyayla değil) tarihi yapıların bir değeri olabilir. Yapıtların başarısı, özgünlüğü ile mümkündür ve bu özgünlük geçmişteki özün değerlendirilip yeniden evrilmesi ile kalıcı ve değerli yapılara dönüşür $(\mathrm{Ku}-$ ran, 2012).

Günümüzde bu geçmiş canlandırmacılığının eklektik bir cephe görünümüne, hatta süslemeye indirgendiği durumlar gözlenmektedir. Mimarlığın özünden uzak olan bu formel yaklaşım, geçmişte malzemenin doğası doğrultusunda bir anlamlı şekillenmiş formları sahte malzemelerle canlandırmayı beraberinde getirmiştir. Oysa yaklaşım, süsleme cinayettir diyen Adolf Loos'un da altını çizdiği gibi mimariyi bir cephe süsleme olgusuna indirgemeden, malzemeye uygun yeni bir dil bulmak olmalıdır. Loos bu sözünü yıllar sonra, düşmanlarının onun her türlü süslemeye karşı olduğu anlamını çıardıklarını ancak kendisinin sadece her tür taklit malzemeye karşı olduğunu söyler (Loos ve Stuiber, 2012). Mimarlık Potemkin Şehri örneğindeki gibi, izlenmek için yapılan sahte sahnelerden farklı olarak, içerisinde hayatı deneyimleyeceğimiz gerçek mekanların üretilmesidir. Tasarım kararları verilirken, tarihten bir referans alınacaksa dahi, biçimsel dilini köklerine kadar keşfetmek, oluşumunu ve gelişimini etkileyen nedenleri analiz etmek, evrensel nedenleri tikelden ayırmak gereklidir. Tüm bunların bilinçli hedeflerle, tasarım için güvenli bir dayanak noktasıyla birleştirilmesi gerekir. Tasarım her ne kadar özgür bir eylemse de, bu kararın sorumluluğunu üstlenmek için, başka bir tasarım kararı alınmasından alıkoyan nedenleri cevaplayabilmek gerekliliğini beraberinde getirir. 
Tablo 1. Mimari kodların kullanımları (Kaynak: Yazarlar)

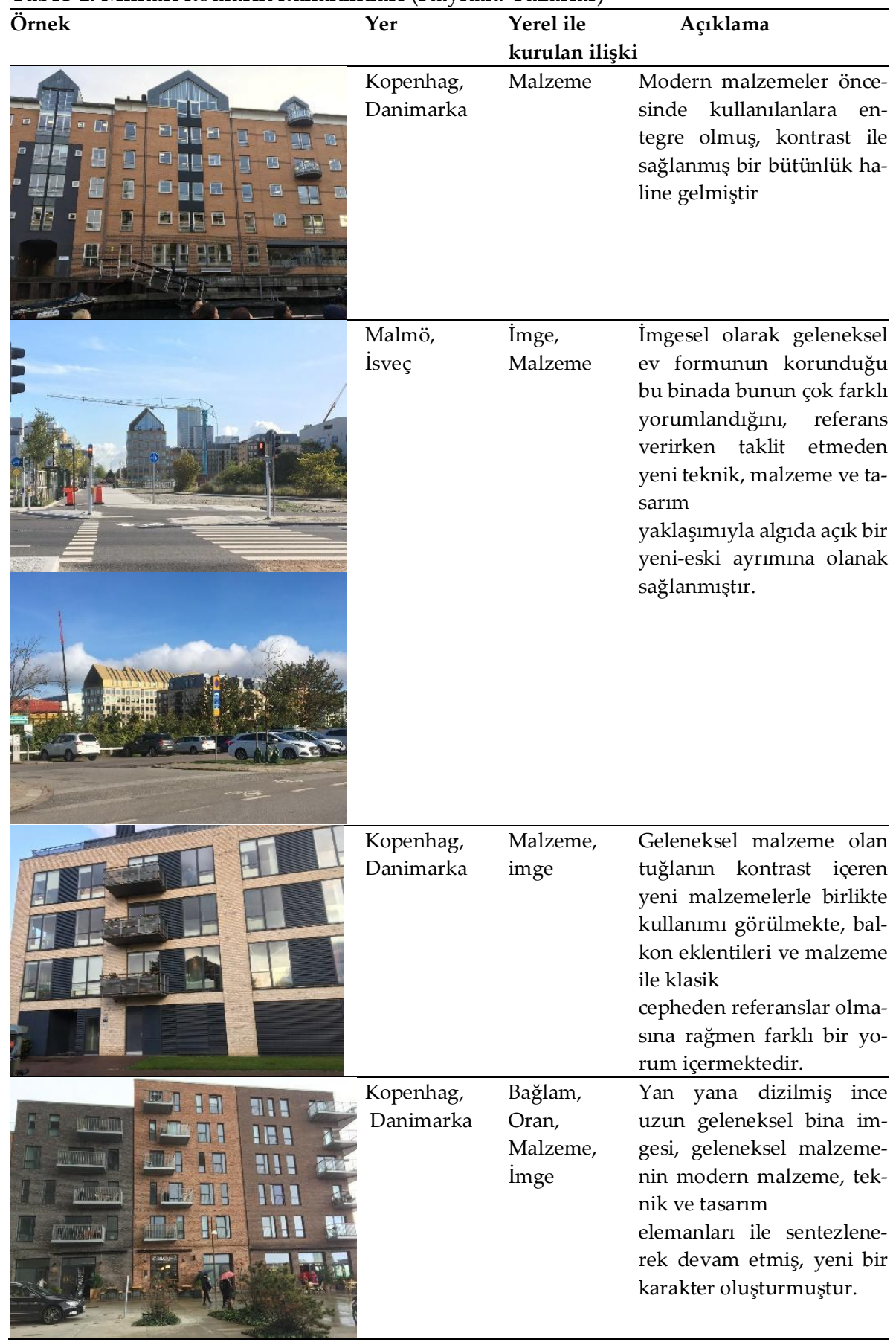




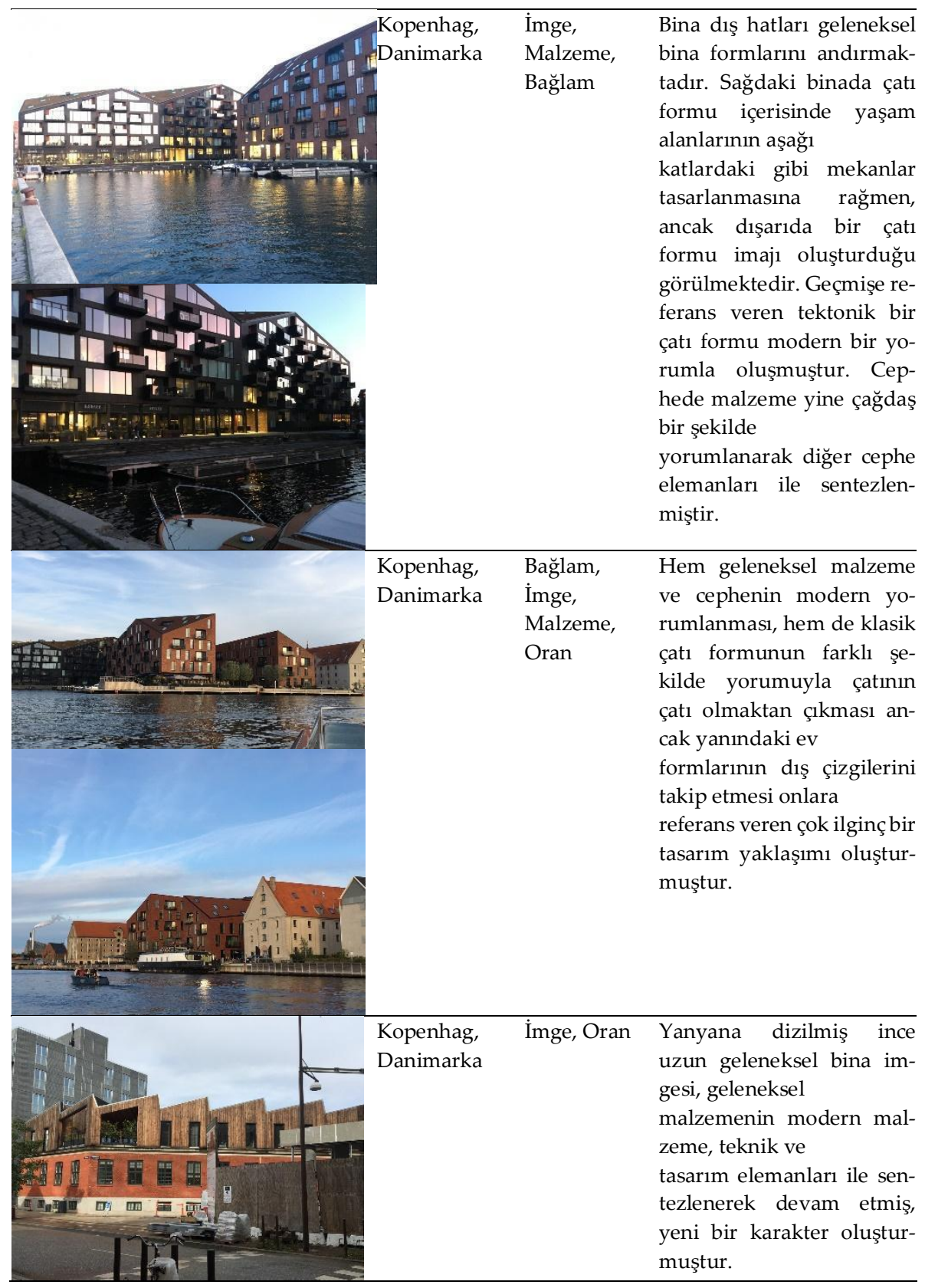

Kentsel mekanların ve şehir kültürlerinin yaratılması ve kullanımının anlaşılmasında kolektif hafızanın önemi büyüktür. Kolektif hafızanın kentsel boyutlara ulaşması çoğunlukla mimari yapı ölçeğinden başlar. Kentli, yapılarla bağ kurarak kenti benimseyebilir. Kentleri yaşanabilir kılan faktörlerden 
biri de kentsel bellekte güçlü bir yer tanımlayabilme potansiyelleridir. Şehirlerin kollektif kimlikleri; paylaşılan anılar, aktarılabilen kültür mirası ve yerel tarih üzerinden şekillenir. Mimari, bu şekillenmenin oluşabilmesi için bir araçtır. Bu bağlamda Kopenhag ve Malmö şehirlerinde saha ziyaretlerinde taklite düşmeyen ve yorum içeren örneklerin bir analizi, mimari kodların kullanımına bir örnek olarak sunulmuştur. (Tablo 1) Örneklerdeki çağdaş yapıların yapısal gelişimini incelediğimizde kaynakların dikkatli kullanıldığı, formların tesadüfi olmadığı, formel sürdürülebilirliğin tasarımın bir parçası olmasının yanı sıra yorumlanarak bağlama ya da geçmişe referanslar verdiği görülmektedir. Burada formlar amaç olmaktan öte, tasarımcının içselleştirilmiş düşüncelerinin dışsal bir sorunla ilişkilendirdiği anlamsal çizgiler doğrultusunda gelişmiştir. Modern düzenlere sahip çatı ve cephe formları geleneksel mimariden ve bağlamdan esinlenen bir üslupla gerçekleştirilmiş; kullanılan yerel ve çağdaş malzemeler, yerel kentsel dokunun imgesel devaml1lığının bir nevi göstergesi haline gelmiştir. Kullanılan malzemelerin yalıtılarak değil, her yapının kendi koşullarında ve bağlamın farklı öğeleriyle kurduğu ilişkiler doğrultusunda keşfedilmesinin amaçlandığı gözlemlenebilmektedir. Dil, üslup ve malzeme birliğine yönelik geliştirilmiş olan sürdürülebilir tavra ek olarak; yapı oranlarının, insan-yapı ilişkisinin kurulabileceği şekilde, insan ölçeği gözetilerek tasarlanmış olması bu şehirlerde kentsel hafızanın kurgulanabilirliği açısından önemli bir faktördür. Bu yaklaşım, koruma problemine ışık tutarak toplumsal belleğin devamlılığına da katkı sağlamaktadır. Bu durumda mimari bir kaliteden de söz edilebilir. Bu nedenle yapı tasarımında geçmişten referans almak isteniyorsa, tasarımcıların da bu hassasiyetleri göz önünde bulundurmaları gereklidir.

\section{Sonuç}

Mimaride görsel formların ve görünmez niteliklerin anlamlarını keşfetmek için dile doğru yoğun bir geçiş olmuştur. Dilin rolü ilişki kurmaktır. Çalışmada altı çizildiği gibi mimari, tasarımın oluşumu ve okunması paralelinde dil ile benzeşmektedir. Anlamsal ve sözdizimsel arasındaki genel ayrım mimaride görülebilir. Mimarın içselleştirilmiş düşünceyle tasarladığ1 gibi mimari form, her zaman dişsal bir sorunla ilişkilendirilmiştir. Kurulmuş olan şifreleme her zaman mimarinin fizyoloji yoluyla anlaşılması, okunması veya düşünülmesi gereken teoriye göre kodlanır. Düşünülebilecek her şey, yeni gelen, unutulan, tekrar hatırlanan kelimeler gibi bir dilde kurgulanabilir. Bu bir nevi yaratıı bir oluşumdur. Bir binanın eklenmesi tıpkı bir dilde konu- 
şurken cümleyi ifade ederkenki oluşum gibidir. Her ikisinin de filolojik olarak genişletilmesi gerekir ve hiçbir zaman yeterince net ve anlaşılır olmayacaktır. Mimaride arkitektonik analizler, uzay ve yer oluşturma etkinliği üzerine bir dizi perspektifin/yakınsamanın sonucudur. Mimari göstergebilim, asgari anlamlı birimler arayışıdır.

Mimaride dil gücünü gelenekler ve kültürel kimlikten alır ve mekanın semantik içeriği anlamlı bir çevrenin inşası işe mümkündür. Eisenmann, biçim sorunlarının bazı eleştirel çerçevelerde sunulduğu diğer disiplinleri incelemeye başlamasının onu dilbilimi ve semantiğe yönlendirdiğini söyler. Bu benzetmeden yola çıkarak mimari ve dil arasında birkaç analoji yapmaya, daha spesifik olarak mimari formun semantik yönleri hakkında bir hipotez oluşturmaya başladığını söyler. Eisenman'ın ilgisi, mimaride bulunan geleneksel yapı biçimlerinin (sütunlar, duvarlar vb.) yeni anlamlara yol açacak şekilde nasıl birleştirilebileceği üzerine olmuştur. Hipotezi, mimarideki formların kendilerini hem duyular tarafından tanınan yüzeysel bir boyutta (doku, renk, şekil) hem de derin bir bakış açısıyla, sadece algılarla akılda tanınan, imge olarak sunulan önlük, eğiklik, durgunluk vb. ilişkileri olarak sunduğudur. (Eisenman ve Kipnis, 2007) Eisenman'ın çalışmalarının benzersiz özelliği, çalışmasını bu genel tutumdan ayırma girişiminde yatmaktadır. Tasarladığı evlerinde, anlamsal yönler, dış referanslara bağlı olmaksızın birbiriyle ilişkili "işaretler" tarafından özümsenmiştir; bulunmayan bir şeyin ikamesi değildir. Bu nedenle, eserleri öncelikle mimarinin sözdizimsel boyutu içinde var olur (GandelsonasveMorton, 1972). Dolayısıyla söylem ve mimarlık arasında derin bir ilişki bulunmaktadır, çünkü her ikisi de düşüncenin görsel imgesini ortaya koyma peşindedir.

Mimaride anlam, birbiriyle ilişkili iki yön açısından tanımlanabilir; ilki, bir binanın bileşenlerini, alt bileşenlerini, sistemlerini ve alt sistemlerini yapılandırmak için bir dizi olasılık; ikincisi, mimari bir bilgi havuzundaki, imgelerin ve fikirlerin bir repertuarıdır. Sonuç olarak inşa edilen binaları okurken yüzeyselliğin ötesinde, tasarım kararlarını şekillendiren nedenlerle birlikte bütüncül bir bakış açısıyla analiz etmek, yeni tasarımlarda da yine bu yüzeysellikten ve şekilcilikten uzak, kullanıcı deneyimlerini önemseyen, mimari kalitesi yüksek mekanlar oluşturulmasını sağlar. Üstelik geçmişte Anadolu'da uygulanan mimari kararlar, süs ve gösteriş gibi yüzeysel konseptlerden öte sade ve fonksiyonel bir üslup doğrultusunda dönem için en uygun mimari tasarım, ölçü/oran/orantı detay çözümü biçim-içerik ilişkisi, bağlam, iklim şartları, insan ölçeği ve güncel yapım teknikleri ve malzeme doğrultusunda belirlenmiştir. Bu tasarım anlayışı çeşitli denemeler aracılığıyla aktif olarak 
bir arayış ve keşif süreci içinde olmuştur. Bunu oluşturan en önemli etken çok çeşitli/farklı kaynaklardan beslenen bu arayıştır (Uluçam, 1999).

$\mathrm{Bu}$ çerçevede, sürdürülmek istenilen mimari anlayışın kodlarını doğru analiz etmek, mimariyi biçimsel tekrarlarla canlandırmacılıktan daha anlamlı bir yöne götürecektir. Çünkü bu gerçek sürdürülebilirlik sağlamanın tek yoludur. Ernst Egli'nin Mimar Sinan eserlerine ilişkin çıarımları mimari kodların biçimin ötesinde bir algı ile analizine örnek olabilecek bir perspektif sunar. Egli Ayasofya etkisini inkar etmeden, Mimar Sinan'ın üslubunun izlerini Anadolu Selçuklu Medeniyetine bağlar. Ona göre Sinan'ın büyüklüğü “Eserlerindeki biçim ve içeriğin tam uyumunda yatar, benzersizliği ise kendisine verilen görevlerin bireysel yönlerini kalıcı ve evrensel bir şeye dönüştürme becerisindedir. Eserlerinin bugün her zamanki gibi canlı kalma nedeni de budur. Bu eserler geçmişin olumsuz özelliklerini muhafaza eder" (Egli, 1967).

Sonuç olarak, çağın gereksinimleri ve buna yönelik uygulamalar kültürel ve sosyal değişimler, teknolojik ve ekonomik gelişmeler paralelinde değiş̧mektedir. Mimarlık farklı dönemlerde güncel sorunlara kendini yenileyen yöntemler ekleyerek çözüm üretmiştir. Bu çözümlerin sürdürülebillirliği çağın ruhunu yakalayan ve mimarinin özünü kaybetmeyen tasarım anlayışı ile mümkündür. Görünenin yalnızca bir parçası olan görsel algı, görülenden daha fazladır. Diğer bir deyişle, görsel algının onu görenin belleğinde yer alan kodları uyarması kimliği açığa çıkarır. Ve bellekteki bu iletişim, kodların doğru okunması ve mimari dil ile yansitılması yoluyla mümkün görülmektedir. Dolayısıyla geleneksel mimarinin 'biçim'den öte içeriğinin muhafaza edilme sorunu bellekteki bu iletişim ağıyla birlikte cevap bulabilir hale gelmektedir. 


\section{Extended Abstract}

\section{Sustainability of Codes And Semantic Language in Design Reading Architecture: A Discourse of Essence, Memory and Identity}

Hatice Kalfaoğlu Hatipoğlu ORCID: 0000-0002-0716-7431
Çiğdem Koç Aytekin

ORCID: 0000-0002-5059-034X

The process of modernism questioning the characteristic style of traditional architecture has brought today's understanding of architecture confronted with an identity debate. With this identity confusion and today's "in-betweenness" in design, the process of adapting the knowledge obtained from previous practices to the new and current environment has brought the problematic of the correct relationship between memory and space into the fore.

It can be indicated that we are in a process where a taste-oriented/subjective design approach prevails in today's Turkish architecture. With the change of sense of taste over time, this view, which leads the discipline of architecture to a temporary fashion, reveals itself with copy and imitation in today's Seljuk-Ottoman facade fashion. This approach causes the reduction of architecture to formalism in civil and public architecture practice in Turkey. Unless the form is a tool for expression and a clue for the intention, form oriented implementations are conducted for the sake of historical revitalization. As an architectural criticism, while discussing the reasons for this need for a return, it is vital to present designs that take into account the current dynamics of our rapidly transforming lives and the principles of architectural design. In the history of architecture, there are cases in which the principles, concepts, forms, symbols, order, and proportions in the memory are repeated or transformed. When examining today's tendency in various periods in the past, it is obvious that the practice applied under the name of "traditional style" and "national identity", actually ignores the context, the requirements and the socio-spatial conditions of the day. Moreover this tendency is far from nature, and is the victim of a virtual and superficial repetition. However, when the development and transformation of Anatolian Turkish architecture in different geographies is evaluated, it is obvious that the choice of style has 
been strongly oriented from concrete environmental / periodic conditions, technological developments, cultural interactions and context rather than formal approaches following a specific ideology or identity definition.

It is necessary to analyse the codes in architecture in order to understand and make sense of the philosophy to be sustained, the choice of style and design decisions of the period. The concept of code refers to the organization or the system that relates the elements or units of any message and provides the possibility for a better comprehension. Although these codes are traditionally considered as a body of architectural ideas structured within a fixed framework, this approach does not explain the complexity of architecture. In order to suggest this complexity, the architectural codes should be accepted as a field of dynamic tensions including oppositions which constitute an empty framework of possible architectonic relationships. Sets of ideas, images and concepts of buildings drawn from the architectural repository go through this framework and provide the creation of synthesis which constitutes architectural form.

The criticized recreational (canlandirmacl) architectural production actually made its debut under the name of national identity. However, it is clear that how far this situation is far away from the original intended and desired attitude. In this context, this study focuses on how the relationship of the architectural product with the preceding and the latter is reflected in practice, and it will be in search of the sustainable spatial memory / meaning / philosophy and identity, in other words, the 'essence'.

In this context, this study aims to reveal how these traces, which are not merely images, should be adapted to today's conditions within the framework of cause and effect relationship with concrete examples. In order to achieve this goal, architectural design was discussed in relation to the codes it contains within the framework of memory-language-meaning, and concrete examples were presented to the reflections of the architectonic codes in line with the experiences and perceptions gained from the authors' observations in the field studies in two cases.

In this study, how characteristic phenomena are used in the design process and how they correspond have been displayed with a few concrete examples. These examples are built on the experiences and perceptions gained from the authors' observations in the field studies in Copenhagen and Malmö. By examining the relationship between 'essence' and 'originality', it has been obtained a concrete platform that can hold on in the future for today's architecture consisting of 'images detached from their identities'. In this 
context, the aim of the study is to investigate how to provide the semantic continuity of local / traditional / qualified architecture with the correct perception of space within the framework of the memory / space debate and try to present it with concrete examples. In this framework, analysing the codes of the architectural understanding that is desired to be sustained leads the architectural understanding in a more meaningful direction than applications following formal repetitions. This is the only way to ensure a real sustainability. As a result, the requirements and the practices of the period change within the context of cultural and social changes, technological and economic developments.

Architecture has produced with the solutions by adding self-renewal processes/methods to current problems in different periods. The sustainability of real solutions of architecture is possible with the understanding of design that captures the spirit of the age and does not lose the essence of architecture. Visual perception, which is only a part of what is seen, is more than what is seen. In other words, when the visual perception stimulates the codes in the memory of the person who sees it, the identity is revealed. And this communication in memory seems possible by reading the codes correctly and reflecting them in architectural language. Therefore, the problem of preserving the content of traditional architecture beyond "form" can be provided with this communication network in memory.

\section{Kaynakça/References}

Assmann, J. (2001). Külttürel bellek: eski yüksek kültürlerde yazı hatırlama ve politik kimlik. İstanbul: Ayrint Yayınları.

Balamir, A., ve Asatekin, G. (1991). Ulusal kimlik sorusu üzerine karşıt düşünceler ve konut mimarisi. Odtü Mfd, 73-87.

Bektaş, C. (2013). Türk evi. İstanbul: Yapı Endüstri Merkezi Yayınları.

Berger, J. (2008). Görme biçimleri. İstanbul: Metis Yayınları.

Bergson, H. (2015). Madde ve bellek. Ankara: Dost Kitabevi.

Bozdoğan, S. (2001). Modernizm ve ulusun inşasl: erken cumhuriyet Türkiye'sinde mimari kültür. İstanbul: Metis Yayınları.

Collins, P. (1959). Concrete: the vision of a new architecture: a study of Auguste Perret and his precursors. New York: Horizon Press.

Corbusier, L. (2000). Şark seyahati. İstanbul: Türkiye İş Bankası Kültür Yayınları.

Crysler, C. G. (2003). Writing spaces: discourses of architecture, urbanism and the built environment, 1960-2000. Abingdon: Routledge.

Eco, U. (1986). Semiotics and the philosophy of language. Bloomington: Indiana University Press.

Egli, E. (1967). Geschichte des stä̈tebaues. Erlenbach-Stuttgart: Rentsch 
Eisenman, P., ve Kipnis, J. (2007). Written into the void: selected writings,1990-2004. London: Yale University Press.

Forty, A. (2000). Words and buildings: a vocabulary of modern architecture. (Vol. 268) London: ThamesveHudson.

Foucault, M. (2002). The archaeology of knowledge. Abingdon: Routledge.

Foucault, M. (1971). The order of discourse in Robert Young. Untying the text: a post-structuralist reader, 48-78.

Gandelsonas, M., ve Morton, D. (1972). On reading architecture. Progressive architecture archives.

Greimas, A. J. (1983). Structural semantics: an attempt at a method. Lincoln: University of Nebraska Press.

Halbwachs, M. (2018). Kolektifbellek. İstanbul: Pinhan Yayıncilik.

Jacobson, R. (1971). Selected writings [of] Roman Jakobson: word and language. New York: Mouton.

Jedlowski, P. (2001). Memory and sociology, themes and issues. Timeve Soicety, 10(1), 2944.

Kuran, A. (2012). Selçuklular'dan Cumhuriyet'e Türkiye'de mimarlık. İstanbul: İş Bankası Yayinlari.

Lefebvre, H. (2014). Mekanın üretimi. İstanbul: Sel Yayıncilı.

Loos, A., ve Stuiber, P. (2012). Adolf Loos - ornament und verbrechen. Wien: Metroverlag.

Morris, C. W. (1970). Foundations of the theory of signs. Illionis: University of Chicago Press.

Öğün, E., ve Öğün, M. (2001). İstanbul'un kıyısında dokuz evlik bir kır yerleşmesi. Arredamento Mimarlik, (100).

Parmaksız, P. M. (2019). Belleğin mekanından, mekanın belleğine: kavramsal bir tartısma. İlefDergisi, 6(1), 7-26.

Preziosi, D. (2008). Presidential address: Reckoning with the world: figure, text and trace in the built environment. The American Journal of Semiotics, 4(1/2), 1-15.

Rasmussen, S. E. (2009). Yaşanan mimari. İstanbul: Remzi Kitabevi.

Remizova, O. (2015). The structure of the architectural language. Architectural studies, 1(2), 81-86.

Serim, S., ve Ünlü, A. (2007). Yapılı çevre üzerinden mimarlık bilgisinin üretilmesi: eleştirel bir değerlendirme. İtü Dergisi, 25-36.

Siza, A. (2015). Apaçıklı̆̆ı imgelemek. İstanbul: Janus Yayınları.

Uluçam, A. (1999). Klasik dönem Osmanlı mimarisi. in Osmanlı (Vol. 10, p. 163-183). Ankara: Yeni Türkiye Yayınları.

Wagner, O. (1990). Modern architecture : a guidebook for his students to this field of art. Calif: Getty Center.

White, H. (1978). Essays in cultural criticism. tropics of discourse. Baltimore: Johns Hopkins UP, 81-100.

Wright, F. L. (1975). In the cause of architecture. New York: Architectural Record Books.

Zevi, B. (1957). Architecture as space: how to look at architecture. New York: Horizon Press. 